\title{
Pediatric primary care in Ontario and Manitoba after the onset of the COVID-19 pandemic: a population-based study
}

\author{
Natasha Saunders MD MSc, Astrid Guttmann MDCM MSc, Marni Brownell PhD, Eyal Cohen MD MSc, \\ Longdi Fu MSc, Jun Guan MSc, Joykrishna Sarkar MSc, Alyson Mahar PhD, Sima Gandhi MSc, \\ Lisa Fiksenbaum PhD, Alan Katz MBChB MSc, Nkiruka Eze MSc, Therese A. Stukel PhD
}

\section{Abstract}

Background: There were large disruptions to health care services after the onset of the COVID-19 pandemic. We sought to describe the extent to which pandemic-related changes in service delivery and access affected use of primary care for children overall and by equity strata in the 9 months after pandemic onset in Manitoba and Ontario.

\begin{abstract}
Methods: We performed a population-based study of children aged 17 years or less with provincial health insurance in Ontario or Manitoba before and during the COVID-19 pandemic (Jan. 1, 2017-Nov. 28, 2020). We calculated the weekly rates of in-person and virtual primary care well-child and sick visits, overall and by age group, neighbourhood material deprivation level, rurality and immigrant status, and assessed changes in visit rates after COVID-19 restrictions were imposed compared to expected baseline rates calculated for the 3 years before pandemic onset.
\end{abstract}

Results: Among almost 3 million children in Ontario and more than 300000 children in Manitoba, primary care visit rates declined to 0.80 (95\% confidence interval [Cl] $0.77-0.82)$ of expected in Ontario and $0.82(95 \% \mathrm{Cl} 0.79-0.84)$ of expected in Manitoba in the 9 months after the onset of the pandemic. Virtual visits accounted for $53 \%$ and $29 \%$ of visits in Ontario and Manitoba, respectively. The largest monthly decreases in visits occurred in April 2020. Although visit rates increased slowly after April 2020, they had not returned to prerestriction levels by November 2020 in either province. Children aged more than 1 year to 12 years experienced the greatest decrease in visits, especially for well-child care. Compared to prepandemic levels, visit rates were lowest among rural Manitobans, urban Ontarians and Ontarians in low-income neighbourhoods.

Interpretation: During the study period, the pandemic contributed to rapid, immediate and inequitable decreases in primary care use, with some recovery and a substantial shift to virtual care. Postpandemic planning must consider the need for catch-up visits, and the long-term impacts warrant further study.

$\mathrm{P}$ rimary health care is essential to maintaining the health of individuals and populations, and the functioning of a health care system. For children in particular, primary care is the cornerstone for monitoring growth and development, providing anticipatory guidance and delivering vaccinations for vaccine-preventable diseases. A good primary care system is associated with more equitable health in populations. ${ }^{1,2}$ Delays in or failure to access regular and timely primary care can lead to service gaps during a period of critical development for children and can further widen health inequities.

In March 2020, the COVID-19 pandemic was declared by the World Health Organization. ${ }^{3}$ Many primary care provider offices closed or functioned at reduced capacity alongside broader shutdowns including nonurgent health care. ${ }^{4,5}$ Care providers reported difficulty keeping offices open owing to multiple factors including lack of personal protective equipment and fear of infection. ${ }^{6}$ To mitigate the challenges to providing care imposed by the shutdown, and to facilitate and maintain isolation, the Ontario and Manitoba ministries of health introduced new virtual care fee codes. ${ }^{7}$

Virtual care is a well-established modality for care delivery, especially for mental health care. Its integration into pediatric primary care for those with a medical home is supported by the American Academy of Pediatrics. ${ }^{8}$ For children, however, for whom growth monitoring, vision screening and vaccinations require in-person visits, needed care may only partially be provided virtually. Virtual care may not be optimal for families with lack of access to a reliable Internet or telephone

\section{Competing interests: None declared.}

This article has been peer reviewed.

Correspondence to: Natasha Saunders, Natasha.saunders@sickkids.ca CMAJ Open 2021 December 14. DOI:10.9778/cmajo.20210161 
service and those with lower virtual health care literacy, and may contribute to inequities in access to or quality of care. Reduction in pediatric primary care (both virtual and in person) as a consequence of nonpharmaceutical interventions $^{9,10}$ and imposed restrictions to reduce spread of SARSCoV-2 infection may lead to lasting health and social consequences for children and their families.

We aimed to understand the extent to which pandemicrelated changes in service delivery and access affected use of primary care for children and adolescents overall and by equity strata in 2 large Canadian provinces, Manitoba and Ontario, with different patterns of SARS-CoV-2 circulation and restrictions. Specifically, our objectives were to examine rates of primary care well-child and sick visits, in person and virtually, before and during the COVID-19 pandemic in Ontario and Manitoba, and to explore the association of sociodemographic factors with use of pediatric primary care during the pandemic.

\section{Methods}

\section{Study design and setting}

We conducted a population-based repeated cross-sectional study of rates of primary care visits for all children and adolescents in Ontario and Manitoba between Jan. 1, 2017, and Nov. 28, 2020, using linked health and administrative data sets. In Ontario, the first "wave" occurred from March to July 2020 and the second wave from September 2020 to February 2021, whereas in Manitoba, these waves occurred in August 2020 and in October 2020 to February 2021, respectively.

\section{Population}

We included children and adolescents (age $\leq 17 \mathrm{yr}$ ) living in Ontario or Manitoba during the study period. We excluded children and youth not residing in Ontario or Manitoba on Jan. 1 of each year and those who were ineligible for provincial health insurance coverage within 90 days of Jan. 1. Newborns (age $<29$ d) were included as a rolling cohort. Newborns were excluded if they did not reside in Ontario or Manitoba, were ineligible for provincial health insurance at birth or had less than 28 days of follow-up at the end of the accrual period.

\section{Data sources}

We used health and demographic databases housed and linked at ICES (Ontario) and the Manitoba Centre for Health Policy (Appendix 1, Table S1, available at www.cmajopen.ca/content/ 9/4/E1149/suppl/DC1). Individual-level records were linked by means of unique encoded identifiers derived from the health care numbers of people eligible for provincial health insurance coverage. We used demographic information (date of birth, sex and postal code) from provincial health insurance registries (Ontario's Registered Persons Database, Manitoba Health Insurance Registry) and physician billings databases (Ontario Health Insurance Plan, Manitoba Medical Services) to ascertain outpatient physician visits to family physicians and pediatricians for primary care, both in person and virtually (Appendix 1, Table S2). ICES data have been shown to be valid for sociodemographic data and physician billing claims. ${ }^{11}$
Equity strata of interest measurable in available administrative data included neighbourhood material deprivation quintile from the Ontario Marginalization Index ${ }^{12}$ and the Canadian Marginalization Index for Manitoba; ${ }^{13}$ rural (community size $<10000$ ) versus urban residence based on the 2016 Canadian census; ${ }^{14}$ and the child's immigrant status (refugee, nonrefugee or Canadian-born) based on presence of a record in the provincial portions of Immigration, Refugees and Citizenship Canada's Permanent Resident Data set. The Permanent Resident Data set includes demographic information for all people who arrived in Ontario from Jan. 1, 1985, to May 31, 2017, and in Manitoba from Jan. 1, 1985, to Dec. 31, 2017. Linkage of Immigration, Refugees and Citizenship Canada data to population registries has been conducted and validated in each province, with a linkage rate of $86 \%$ in Ontario and $96.2 \%$ in Manitoba. ${ }^{15,16}$ Those whose date of eligibility for provincial health insurance coverage was after May 31, 2017 (Ontario) or Dec. 31, 2017 (Manitoba) were not included in immigrant and refugee analyses as they may have represented interprovincial migrants. Immigrant analyses excluded all children less than 3 years of age owing to data availability.

\section{Primary outcome measures}

Our main outcome measures included overall rates of primary care visits (in person and virtual) to a pediatrician or family physician (Appendix 1, Table S2). We further examined visits by type, including well-child visits (periodic health visits with or without vaccinations) $)^{17,18}$ and sick visits (all other non-well-child visits).

\section{Statistical analysis}

We conducted Ontario and Manitoba analyses separately because the large Ontario population (relative to Manitoba) would have obscured Manitoba's findings had analyses been combined.

We expressed visit rates as total visits per 1000 eligible population, computed overall and by subgroups of clinically relevant age groups, with age defined on the day of the visit $^{19,20}(<28 \mathrm{~d}, 29-365 \mathrm{~d},>1 \mathrm{yr}$ to $5 \mathrm{yr}, 6-12 \mathrm{yr}$ and 13-17 yr), material deprivation quintile, rurality and immigrant status. Individual newborns were followed for 28 days after birth. For nonnewborns, we aggregated daily visit counts to strata of age group, sex and week, and used the corresponding population on Jan. 1 of each year as the denominator for rates as it did not change substantially over the year.

The exposure was the period of the implementation of COVID-19 restrictions to the end of complete data availability, defined as Mar. 1 to Nov. 30, 2020. We used Poisson generalized estimating equation models for clustered count data to model pre-COVID-19 trends and used these to predict expected trends in the 9 months after the onset of COVID-19 in the absence of restrictions. The unit of analysis was the age group-sex-week stratum. The dependent variable was the count of events to the population in the stratum; the offset was $\log$ of the stratum-specific population; and the working correlation structure was AR(1). The pre-COVID-19 model included age group-sex indicators, a linear term of weeks since Jan. 1, 2017 , to estimate the general trend in visit rates through Mar. 1, 2020, and pre-COVID-19 month indicators to model seasonal 
variations, with April as the reference month. The 3 years of prepandemic data was to allow for sufficient stability in preCOVID-19 visit rates and population denominators.

We computed expected visit rates in the 9 months after the onset of pandemic restrictions (and 95\% confidence intervals [CIs]) by applying the linear combination of pre-COVID-19 regression coefficients to the post-onset age-sex-month strata and exponentiating. We expressed the relative change in postonset visit rates as an adjusted rate ratio of observed to expected rates by exponentiating the difference of observed and expected post-onset log rates and CIs. We used Poisson regression for newborn models, with individual newborn as the unit of analysis and similar model terms but without an autoregressive correlation term.
Statistical analyses were conducted with SAS statistical software, version 9.4 (SAS Institute).

\section{Ethics approval}

The Research Ethics Board at The Hospital for Sick Children and the Health Research Ethics Board at the University of Manitoba approved this study.

\section{Results}

Characteristics of Ontario children (almost 3 million) and Manitoba children (> 300000 ) eligible for provincial health care in 2017, 2018, 2019 and 2020 are presented in Table 1 (Appendix 1, Table S3). During the pre-COVID-19 period,

\section{Table 1: Baseline demographic characteristics of children and adolescents aged 17 years or less in Ontario and Manitoba, January} 2017-November 2020

\begin{tabular}{|c|c|c|c|c|c|c|c|c|}
\hline \multirow[b]{2}{*}{ Characteristic } & \multicolumn{4}{|c|}{ Ontario; year; no. (\%) of children* } & \multicolumn{4}{|c|}{ Manitoba; year; no. (\%) of children* } \\
\hline & $\begin{array}{c}2017 \\
n=2761302\end{array}$ & $\begin{array}{c}2018 \\
n=2776698\end{array}$ & $\begin{array}{c}2019 \\
n=2800407\end{array}$ & $\begin{array}{c}2020 \\
n=2829172\end{array}$ & $\begin{array}{c}2017 \\
n=306813\end{array}$ & $\begin{array}{c}2018 \\
n=310111\end{array}$ & $\begin{array}{c}2019 \\
n=311212\end{array}$ & $\begin{array}{c}2020 \\
n=313395\end{array}$ \\
\hline \multicolumn{9}{|l|}{ Age† } \\
\hline Mean \pm SD & $8.70 \pm 5.13$ & $8.70 \pm 5.12$ & $8.72 \pm 5.12$ & $8.73 \pm 5.11$ & $8.96 \pm 5.17$ & $8.95 \pm 5.16$ & $8.93 \pm 5.13$ & $8.96 \pm 5.11$ \\
\hline Median (IQR) & $9(4-13)$ & $9(4-13)$ & $9(4-13)$ & $9(4-13)$ & $9(4-13)$ & $9(4-13)$ & $9(4-13)$ & $9(4-13)$ \\
\hline \multicolumn{9}{|l|}{ Age group } \\
\hline$\leq 28 \mathrm{~d} \neq$ & 140537 & 139911 & 139901 & $115778 \S$ & 17282 & 16885 & 16618 & $14782 \S$ \\
\hline $29-365 d$ & $131375(4.8)$ & $130602(4.7)$ & $130260(4.7)$ & $130494(4.6)$ & $15698(5.1)$ & $15883(5.1)$ & $15955(5.1)$ & $15530(5.0)$ \\
\hline$>1$ to $5 \mathrm{yr}$ & 742356 (26.9) & 744524 (26.8) & $746450(26.7)$ & 753127 (26.6) & 87222 (28.4) & $88136(28.4)$ & 88303 (28.4) & $88369(28.2)$ \\
\hline $6-12 \mathrm{yr}$ & $1096809(39.7)$ & 1107217 (39.9) & $1121055(40.0)$ & $1132943(40.0)$ & $120121(39.2)$ & $122353(39.5)$ & $124220(39.9)$ & $126181(40.3)$ \\
\hline $13-17 \mathrm{yr}$ & $790762(28.6)$ & $794355(28.6)$ & $802642(28.7)$ & $812608(28.7)$ & $83772(27.3)$ & $83739(27.0)$ & $82734(26.6)$ & $83315(26.6)$ \\
\hline \multicolumn{9}{|l|}{ Sex } \\
\hline Female & $1344457(48.7)$ & $1352005(48.7)$ & $1363728(48.7)$ & $1377931(48.7)$ & $149272(48.7)$ & $150890(48.7)$ & $151469(48.7)$ & $152583(48.7)$ \\
\hline Male & 1416845 (51.3) & $1424693(51.3)$ & $1436679(51.3)$ & $1451241(51.3)$ & $157541(51.4)$ & $159221(51.3)$ & $159743(51.3)$ & $160812(51.3)$ \\
\hline \multicolumn{9}{|l|}{ Rurality } \\
\hline Urban & $2485062(90.0)$ & 2497901 (90.0) & 2518679 (89.9) & 2543736 (89.9) & $210245(68.5)$ & $212892(68.7)$ & $213045(68.5)$ & $213820(68.2)$ \\
\hline Rural & $269754(9.8)$ & $271559(9.8)$ & $273500(9.8)$ & $275592(9.7)$ & $96568(31.5)$ & $97219(31.3)$ & $97758(31.4)$ & $98773(31.5)$ \\
\hline Missing & $6486(0.2)$ & $7238(0.3)$ & $8228(0.3)$ & $9844(0.3)$ & $0(0.0)$ & $<6 \rrbracket$ & $409(0.1)$ & $802(0.3)$ \\
\hline \multicolumn{9}{|c|}{ Material deprivation quintile } \\
\hline Q1 (lowest) & $629475(22.8)$ & 643277 (23.2) & $658048(23.5)$ & $672771(23.8)$ & $61371(20.0)$ & $62077(20.0)$ & $62231(20.0)$ & $62686(20.0)$ \\
\hline Q2 & $584527(21.2)$ & $588752(21.2)$ & $594765(21.2)$ & $601189(21.2)$ & $61291(20.0)$ & $61858(19.9)$ & $62195(20.0)$ & $62624(20.0)$ \\
\hline Q3 & $509432(18.4)$ & $509138(18.3)$ & 511701 (18.3) & $514908(18.2)$ & $61413(20.0)$ & $61986(20.0)$ & $62222(20.0)$ & $62696(20.0)$ \\
\hline Q4 & $470261(17.0)$ & $468997(16.9)$ & $469988(16.8)$ & $472749(16.7)$ & $61209(19.9)$ & $61852(19.9)$ & $62144(20.0)$ & $62437(19.9)$ \\
\hline Q5 (highest) & $535311(19.4)$ & $533274(19.2)$ & $531452(19.0)$ & $531273(18.8)$ & $61357(20.0)$ & $62078(20.0)$ & $62257(20.0)$ & $62874(20.1)$ \\
\hline Missing & 32296 (1.2) & 33260 (1.2) & 34453 (1.2) & $36282(1.3)$ & $172(0.1)$ & $260(0.1)$ & $163(0.1)$ & $78(0.0)$ \\
\hline \multicolumn{9}{|l|}{ Immigrant status } \\
\hline Nonrefugee & $141985(5.1)$ & $126321(4.5)$ & $109697(3.9)$ & 95549 (3.4) & $27487(9.0)$ & $27444(8.8)$ & $24174(7.8)$ & $21207(6.8)$ \\
\hline Refugee & $41434(1.5)$ & $37658(1.4)$ & 33328 (1.2) & $29522(1.0)$ & $3736(1.2)$ & 3867 (1.2) & $3321(1.1)$ & $2887(0.9)$ \\
\hline Canadian-born & $2577883(93.4)$ & 2571754 (92.6) & 2566491 (91.6) & 2559252 (90.5) & $275590(89.8)$ & 277451 (89.5) & 275776 (88.6) & 275386 (87.9) \\
\hline Not available & $<69$ & 40965 (1.5) & 90891 (3.2) & $144849(5.1)$ & $0(0.0)$ & $1349(0.4)$ & $7941(2.6)$ & $13915(4.4)$ \\
\hline $\begin{array}{l}\text { Note: IQR = interqu } \\
\text { *Except where note } \\
\text { †On Jan. } 1 . \\
\text { †Not included in the }\end{array}$ & $\begin{array}{l}\text { range, } Q=\text { quint } \\
\text { nerwise. }\end{array}$ & $\mathrm{D}=$ standard de & & & & & & \\
\hline
\end{tabular}




\section{Research}

\begin{tabular}{|llll|}
\hline - Overall visits observed & - Well-child visits observed & - Sick visits observed $\quad-$ Virtual visits \\
-- Overall visits expected & -- Well-child visits expected & $=$ Sick visits expected
\end{tabular}

A

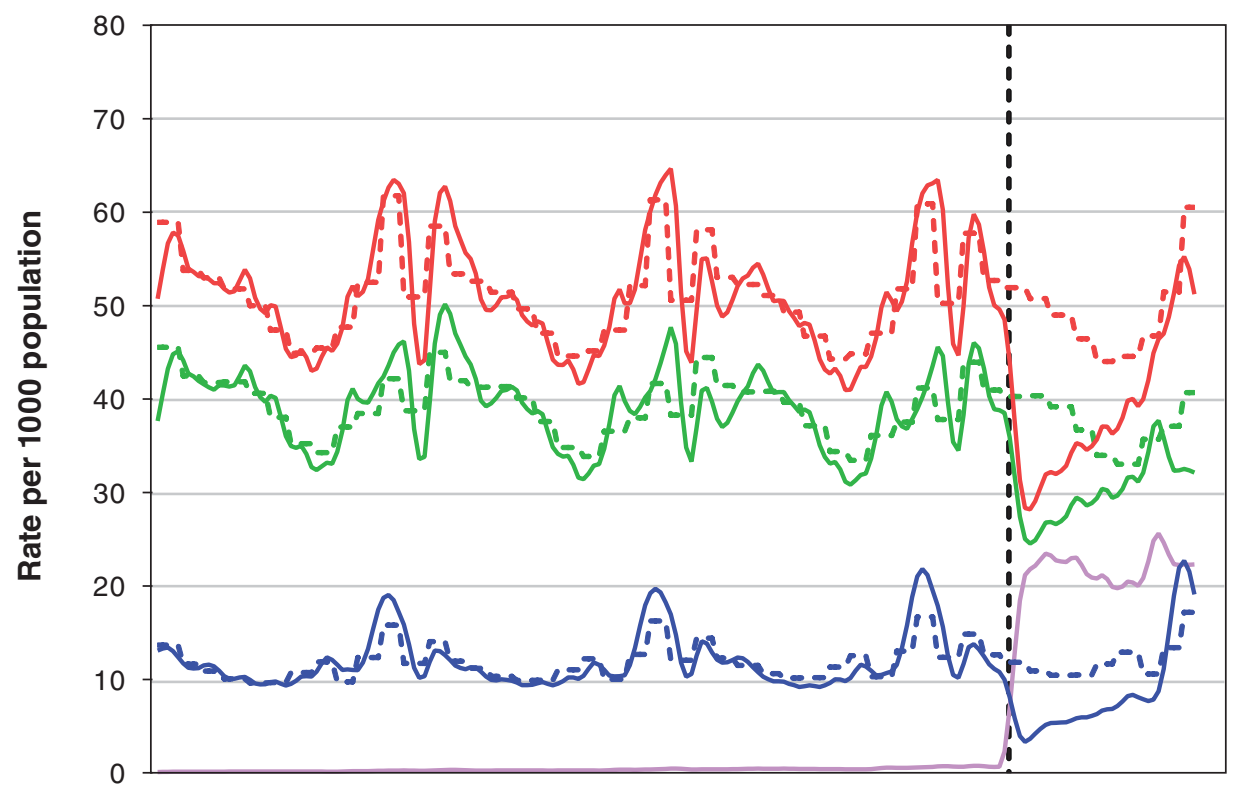

B

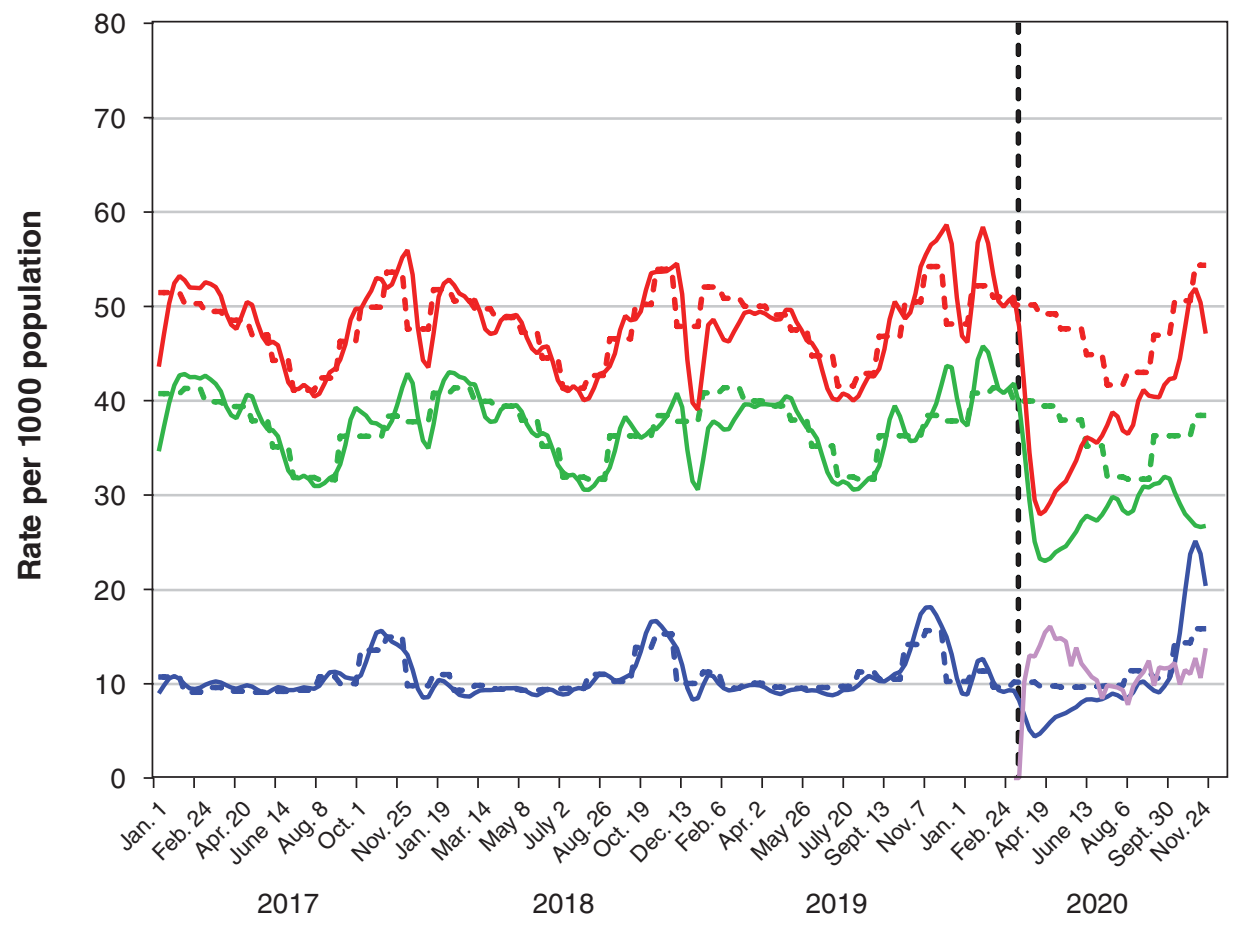

Figure 1: Observed and expected rates of well-child and sick visits to primary care per 1000 population in Ontario (A) and Manitoba (B), January 2017-November 2020. In Manitoba, there was no code for virtual visits before the pandemic. Vertical dashed line represents onset of COVID-19 pandemic restrictions. 
overall weekly visit rates per 1000 population were 49.5 in Ontario and 46.7 in Manitoba (Figure 1). The corresponding rates for well-child visits were 12.2 and 11.2 , and for sick visits, 37.4 and 36.5 .

In the 9 months after pandemic restrictions were imposed, primary care visit rates decreased overall (Figure 1); rates were 0.80 (95\% CI $0.77-0.82)$ of expected in Ontario and 0.82 (95\% CI 0.79-0.84) of expected in Manitoba (Figure 2; Appendix 1, Table S4). In this period, 53\% of visits in Ontario and 29\% of those in Manitoba took place virtually.

Primary care visit rates reached a nadir in April 2020, after which they slowly increased, peaking in November 2020 (Appendix 1, Table S4). The extent of the decline was greatest for well-child visits in Ontario (adjusted rate ratio 0.73, 95\% CI $0.66-0.80$ ) and for sick visits in Manitoba (adjusted rate ratio $0.78,95 \%$ CI $0.75-0.81$ ).

\section{Age groups}

In Ontario, all age groups except newborns experienced a sharp immediate decrease in well-child visits after pandemic restrictions were imposed, with some recovery by November 2020 (Figures 2 and 3; Appendix 1, Tables S5 and S6). Among newborns, well-child visits were lower than and sick visits were higher than expected levels. For sick visits among those aged 29-365 days, visit rates were at or above expected levels, whereas for all children more than 1 year of age, they were well below expected levels (Appendix 1, Table S5).

In Manitoba, newborn well-child visit rates were similar to expected, but sick visit rates were above expected levels (Appendix 1, Table S6). As in Ontario, Manitoba children aged more than 1 year had lower than expected rates of both well-child and sick visits, with some return toward baseline for well-child visits in the final 2 months of the study period.

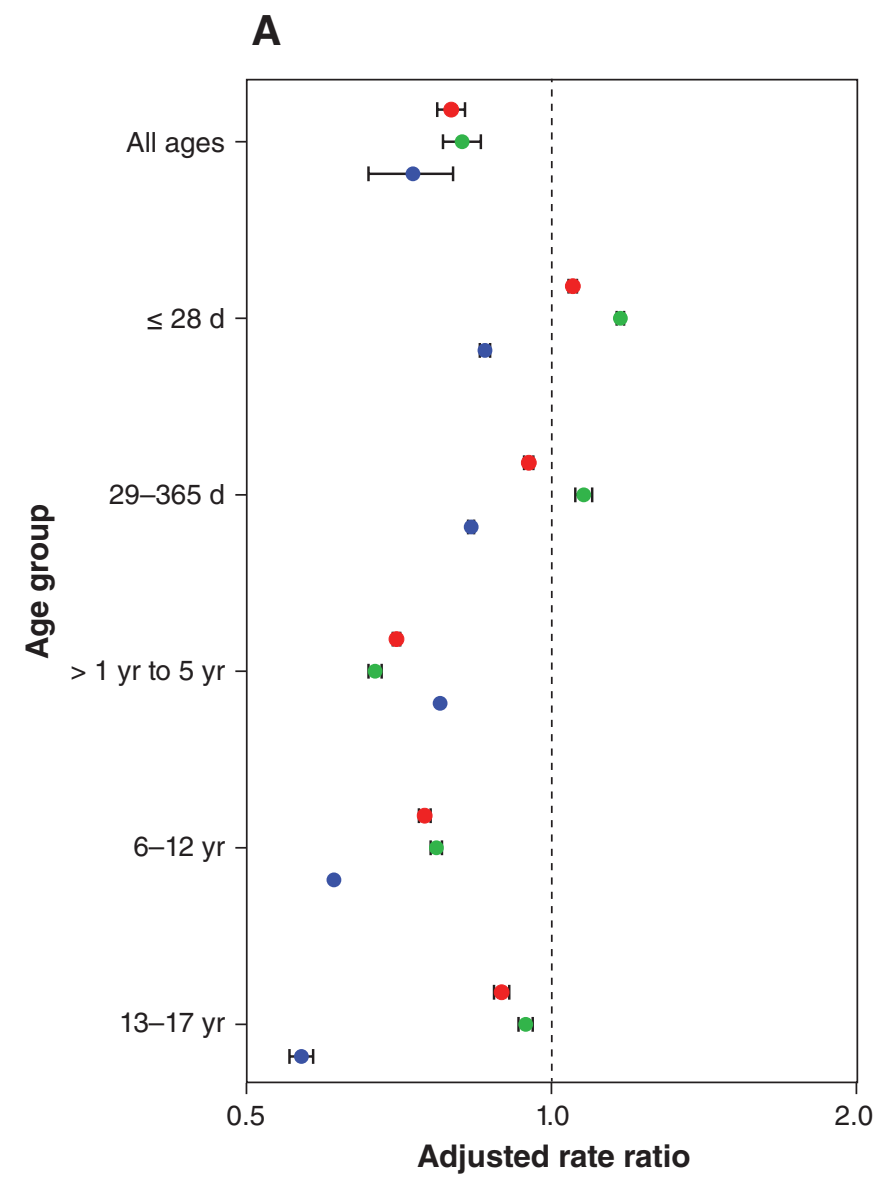

B

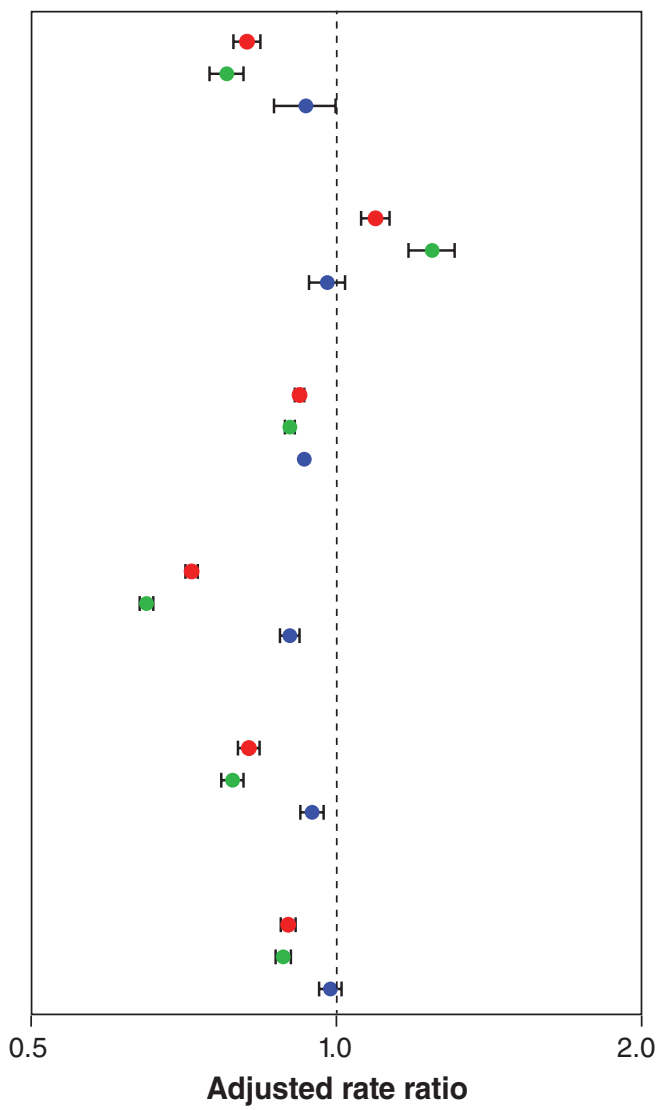

- All primary care Well-child visits - Sick visits

Figure 2: Adjusted rate ratio (of observed to expected rates) of primary care visits in the 9 months after the onset of COVID-19 pandemic restrictions compared to the 3 years before the restrictions, overall and by age group, in Ontario (A) and Manitoba (B). Error bars represent $95 \%$ confidence intervals. 


\section{Research}

Figure 3: Observed and expected rates of well-child and sick visits to primary care per 1000 population by age group. (A) Ontario $\leq 28$ days, (B) Manitoba $\leq 28$ days, (C) Ontario 29-365 days, (D) Manitoba 29-365 days, (E) Ontario >1 year to 5 years, $(F)$ Manitoba $>1$ year to 5 years, (G) Ontario 6-12 years, (H) Manitoba 6-12 years, (I) Ontario 13-17 years, (J) Manitoba 13-17 years. Vertical dashed line represents onset of COVID-19 pandemic restrictions. 


\section{Material deprivation}

We found a small gradient in observed versus expected visit rates by neighbourhood material deprivation quintile. Those in the most deprived quintile had the lowest relative visit rates compared to expected in Ontario but not Manitoba (Figure 4; Appendix 1, Figure S1, Tables S7 and S8). Uptake of virtual care was lowest in the most deprived quintile for Ontario but not Manitoba (Ontario: $54.6 \%$ in quintile 1 v. $50.1 \%$ in quintile 5; Manitoba: $27.9 \%$ in quintile 1 v. $32.0 \%$ in quintile 5) (Appendix 1, Table S13).

\section{Rurality}

The largest decreases in adjusted relative rates in overall primary care visits were observed for urban Ontarians (adjusted rate ratio 0.79 , 95\% CI $0.77-0.82$ ) and rural Manitobans (adjusted rate ratio 0.78 , 95\% CI $0.75-0.80)$. These declines were most pronounced for sick visits in Ontario and wellchild visits in Manitoba (Figure 4; Appendix 1, Figure S2, Tables S9 and S10).

\section{Immigrant status}

Refugees and immigrants to Manitoba had similar rates of well-child visits as Canadian-born children after the onset of pandemic restrictions, with rates at or near expected (Figure 4; Appendix 1, Figure S3, Tables S11 and S12). Sick visit rates were lower than expected among these groups, with Canadian-born children (adjusted rate ratio $0.80,95 \%$ CI $0.78-0.83$ ) experiencing a greater relative decrease than refugees (adjusted rate ratio $0.91,95 \% \mathrm{CI}$ 0.86-0.97).

In contrast, Ontario well-child visits were well below expected across all groups, with lowest rates observed among nonrefugee immigrants (adjusted rate ratio 0.54, 95\% CI $0.51-0.58)$. Sick visit rates were similarly low across groups. In Ontario, a smaller proportion of visits were virtual for refugees $(49.5 \%)$ than for immigrants $(61.2 \%)$ and Canadianborn children $(52.7 \%)$. Uptake of virtual care was generally much lower in Manitoba than in Ontario, with lowest rates among refugees (22.1\%) (Appendix 1, Table S13).

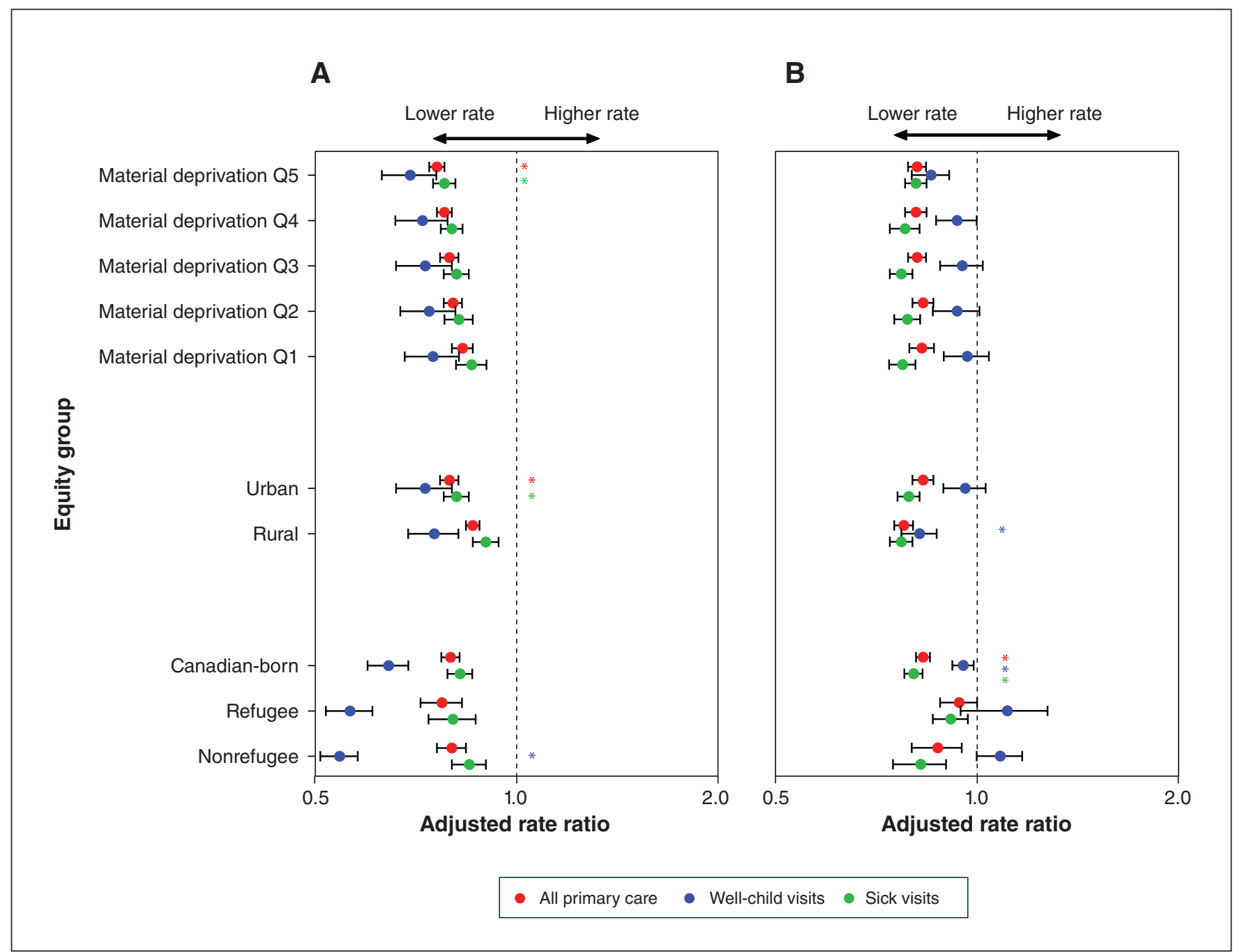

Figure 4: Adjusted rate ratio of primary care visits after the onset of COVID-19 pandemic restrictions compared to the 3 years before restrictions, by neighbourhood material deprivation quintile $(Q)$, rurality and immigrant status, in Ontario $(A)$ and Manitoba (B). Error bars represent $95 \%$ confidence intervals (Cls). ${ }^{*}=$ Cls do not overlap other groups (e.g., material deprivation quintile 5 v. 1, urban v. rural). 


\section{Interpretation}

In this population-based study of children and adolescents in 2 Canadian provinces, we found a large, rapid decrease in primary care use in the first 9 months after COVID-19 pandemic restrictions were imposed. Much of primary care for children was delivered virtually, especially in Ontario. Wellchild visits for vaccinations and growth and development surveillance occurred at about three-quarters the rate in previous years in Ontario but at close to expected levels in Manitoba. Such interprovincial differences were unexpected. Importantly, we found small disparities in the extent of shifts in primary care in Ontario but not in Manitoba, with a disproportionate reduction in essential well-child care for children and adolescents from immigrant and refugee families, of low socioeconomic status and from urban neighbourhoods. Although delays and reductions in primary care were expected given the large disruptions to service delivery and decreased transmission of other infectious agents, the decline in primary care delivery persisted through the first 9 months of the pandemic, including during periods when little virus was circulating, personal protective equipment was more available and infection control measures were in place.

In Ontario, Glazier and colleagues ${ }^{21}$ reported a $28 \%$ decrease in primary care visits in the first few months after the pandemic onset across all ages, with more pronounced effects among children. We also found a rapid decrease in observed visits rates in Ontario as well as Manitoba, but the extent of change, especially for well-child care, was less in Manitoba. Lower SARS-CoV-2 disease activity in Manitoba may explain this finding. ${ }^{22}$ In both provinces, the use of virtual care declined in the later months of 2020. The levels at which virtual care will be sustained, and the longer-term impact on child health, access to care and quality of care of this widespread shift to virtual care remain to be determined.

More transient visit declines after the onset of the pandemic have been described elsewhere. In Chicago, well-child and vaccination visits decreased to half of prepandemic levels and then returned to more than $90 \%$ of the prior year within 8 weeks. ${ }^{23}$ In South Africa, there was a rapid decrease in pediatric primary care, followed by a rapid return to baseline within 3 months. ${ }^{24}$ In jurisdictions where telemedicine remuneration did not match that of in-person visits (e.g., Chicago), virtual care uptake was low $(<10 \%){ }^{23}$ It is possible that, in Ontario and Manitoba, adequate remuneration for virtual care may have facilitated access to care for some families ${ }^{25}$ and the observed interprovincial differences may have been fuelled by the volume of circulating virus (and consequent restrictions) within either province. ${ }^{26}$ In parallel with these observed changes in primary care, a substantial shift in caregiver and family health-seeking behaviour for acute care and after-hours ambulatory care was reported in Canada and elsewhere, with large, rapid declines in visits after the pandemic onset..$^{2,27,28}$ Despite these changes in use of health care services, there has been no reported change in clinical severity or increase in severe harm. ${ }^{2}$
Although other investigators have documented the rapid decline in both primary and acute care use after the onset of the COVID-19 pandemic, few have reported on socioeconomic and demographic disparities of observed changes. ${ }^{2,27,28}$ The pandemic has magnified structural factors underpinning global health inequities, ${ }^{29-31}$ and our findings show that, at least in Ontario, primary care for children may have also been affected. Schweiberger and colleagues ${ }^{32}$ reported that white non-Hispanic children in the United States were more likely to have a preventive or telemedicine visit than other racial groups. Our findings of particularly low well-child visit rates among those from more materially deprived neighbourhoods in Ontario may be explained by amplification of challenges accessing and navigating the health care system, virtual care literacy and access, and heightened fear of seeking care driven by high levels of infection in these communities. ${ }^{33-35}$ Equitable primary care use observed in Manitoba may be related to more centralized delivery of pediatric primary care through hospital-based clinics that serve large proportions of urban, refugee and low-income children. ${ }^{36}$ The role providers had in contributing to these shifts in primary care delivery is unclear; possible factors include a lack of personal protective equipment, workforce redeployment, capacity for virtual care delivery and practice jurisdiction.

\section{Limitations}

One strength of this study is complete population coverage spanning the first 9 months after COVID-19 pandemic restrictions were imposed across 2 Canadian provinces with different SARS-CoV-2 disease activity. Limitations include that virtual care codes did not allow us to differentiate telephone and video visits, the latter of which may be better suited to clinical assessment of children. Similarly, fee codes have not been validated to distinguish well-child from sick visits, and these codes are commonly used in Ontario and Manitoba to measure primary care use. However, immunization codes have been validated to distinguish these visits, and vaccinations typically occur at well-child visits. ${ }^{17}$

We did not have individual measures of sociodemographic characteristics or family composition, although neighbourhood-level measures have been shown to have important associations with health outcomes. ${ }^{37} \mathrm{We}$ did not assess provider-level characteristics, which may be important to understand drivers of inequities and reduced care access during the pandemic. Salaried physician care and some nonphysician care $\left(<1 \%\right.$ of population), ${ }^{38}$ including that provided by community health centres, nurse practitioners and social workers, were not included owing to data availability, but such providers care disproportionately for more marginalized populations. ${ }^{38}$

\section{Conclusion}

We found large and rapid decreases in primary care visits for well-child care, vaccinations and sickness in the 9 months after the onset of the COVID-19 pandemic in Ontario and Manitoba, with a substantial proportion of care delivered virtually. Ontarian but not Manitoban children of low socioeconomic 
status and from urban neighbourhoods had slightly lower visit rates compared to expected. The pandemic, and measures instituted to lessen its impact, may have threatened essential elements of primary care, including mechanisms to mitigate spread of vaccine-preventable diseases, ensure early identification of developmental concerns and reduce health inequities. The longer-term impact on child development and health and vaccine coverage remains to be determined, and understanding health care provider factors contributing to the shifts warrants further study.

\section{References}

1. Starfield B, Shi L, Macinko J. Contribution of primary care to health systems and health. Milbank Q 2005;83:457-502.

2. Williams TC, MacRae C, Swann OV, et al. Indirect effects of the COVID-19 pandemic on paediatric healthcare use and severe disease: a retrospective national cohort study. Arch Dis Child 2021;106:911-7.

3. WHO Director-General's opening remarks at the media briefing on COVID19 [press release]. Geneva: World Health Organization; 2020 Mar. 11. Available: https://www.who.int/director-general/speeches/detail/who-director -general-s-opening-remarks-at-the-media-briefing-on-covid-19---11-march-2020 (accessed 2020 Nov. 3).

4. COVID-19 collection: primary care COVID-19 survey: Larry Green Center and Primary Care Collaborative. Ann Fam Med. Available: https://www. annfammed.org/content/covid-19-collection-primary-care-covid-19-survey-larry -green-center-and-primary-care (accessed 2021 June 5).

5. Quick COVID-19 primary care survey of clinicians: summary of the third (April 24-27, 2020) pan-Canadian survey of frontline primary care clinicians' experience with COVID-19. Primary and Integrated Health Care Innovations Network; 2020. Available: https://spor-pihci.com/wp-content/uploads/2020/ 05/PIHCIN-Covid-19-survey-report-3.pdf (accessed 2021 Jan. 4).

6. Heintzman J, O'Malley J, Marino M, et al. SARS-CoV-2 testing and changes in primary care services in a multistate network of community health centers during the COVID-19 pandemic. FAMA 2020;324:1459-62.

7. Changes to the Schedule of Benefits for Physician Services (schedule) in response to COVID-19 influenza pandemic effective March 14, 2020 [INFOBulletin]. Health Services Branch, Ontario Ministry of Health; 2020. Available: https://www.health.gov.on.ca/en/pro/programs/ohip/bulletins/4000/ bul4745.aspx (accessed 2021 June 10).

8. Committee on Pediatric Workforce; Marcin JP, Rimsza ME, Moskowitz WB. The use of telemedicine to address access and physician workforce shortages. Pediatrics 2015;136:202-9.

9. Calibrating long-term non-pharmaceutical interventions for COVID-19. Manila: Regional Office for the Western Pacific, World Health Organization; 2020.

10. Nonpharmaceutical interventions (NPIs). Atlanta: Centers for Disease Control and Prevention; reviewed 2020 Apr. 27. Available: https://www.cdc.gov/ nonpharmaceutical-interventions/index.html (accessed 2021 Sept. 14).

11. Williams JI, Young W. Appendix I: Summary of studies on the quality of health care administrative databases in Canada. In: Goel V, Williams JI, Anderson GM, et al., editors. Patterns of health care in Ontario. The ICES practice atlas. 2nd ed. Ottawa: Canadian Medical Association; 1996:339.

12. Matheson FI, van Ingen T. 2016 Ontario Marginalization Index: user guide. Toronto: St. Michael's Hospital; Public Health Ontario; 2018.

13. Matheson FI, Dunn JR, Smith KLW, et al. Development of the Canadian Marginalization Index: a new tool for the study of inequality. Can 7 Public Health 2012;103(Suppl 2):S12-6.

14. Data products, 2016 census. Ottawa: Statistics Canada; modified 2021 Feb. 8. Available: https://www12.statcan.gc.ca/census-recensement/2016/dp-pd/index -eng.cfm (accessed 2021 Aug. 30).

15. Chiu M, Lebenbaum M, Lam K, et al. Describing the linkages of the Immigration, Refugees and Citizenship Canada Permanent Resident Data and Vital Statistics Death registry to Ontario's administrative health database. BMC Med Inform Decis Mak 2016;16:135.

16. Urquia ML, Walld R, Wanigaratne $\mathrm{S}$, et al. Linking national immigration data to provincial repositories: the case of Canada. Int 7 Popul Data Sci 2021;6:1412.

17. Schwartz KL, Tu K, Wing L, et al. Validation of infant immunization billing codes in administrative data. Hum Vaccin Immunother 2015;11:1840-7.

18. Wilson SE, Wilton AS, Young J, et al. Assessing the completeness of infant and childhood immunizations within a provincial registry populated by parental reporting: a study using linked databases in Ontario, Canada. Vaccine 2020;38:5223-30.

19. Rourke Baby Record. Ottawa: Canadian Paediatric Society; updated 2021 Oct. 1. Available: https://www.cps.ca/en/tools-outils/rourke-baby-record (accessed 2019 Jan. 24).

20. An update to the Greig Health Record: executive summary [position statement]. Ottawa: Canadian Paediatric Society; 2016. Available: https://www.cps. $\mathrm{ca} / \mathrm{en} /$ documents/position/greig-executive-summary (accessed $2021 \mathrm{Sept} .9$ ).
21. Glazier RH, Green ME, Wu FC, et al. Shifts in office and virtual primary care during the early COVID-19 pandemic in Ontario, Canada. CMA7 2021;193: E200-10.

22. Cases and risk of COVID-19 in Manitoba. Winnipeg: Government of Manitoba. Available: https://www.gov.mb.ca/covid19/updates/cases.html (accessed 2021 June 7).

23. Macy ML, Huetteman P, Kan K. Changes in primary care visits in the 24 weeks after COVID-19 stay-at-home orders relative to the comparable time period in 2019 in metropolitan Chicago and northern Illinois. 7 Prim Care Community Health 2020;11:2150132720969557.

24. Siedner MJ, Kraemer JD, Meyer MJ, et al. Access to primary healthcare during lockdown measures for COVID-19 in rural South Africa: a longitudinal cohort study. medRxiv 2020 May 20. doi: 10.1101/2020.05.15.20103226.

25. Basu S, Phillips RS, Phillips RL, et al. Primary care practice finances in the United States amid the COVID-19 pandemic. Health Aff (Milwood) 2020;39: 1605-14.

26. COVID-19 intervention timeline in Canada. Ottawa: Canadian Institute for Health Information; 2021. Available: https://www.cihi.ca/en/covid-19 -intervention -timeline-in-canada (accessed 2021 July 11).

27. Goldman RD, Grafstein E, Barclay N, et al. Paediatric patients seen in 18 emergency departments during the COVID-19 pandemic. Emerg Med 7 2020; 37:773-7.

28. Dann L, Fitzsimons J, Gorman KM, et al. Disappearing act: COVID-19 and paediatric emergency department attendances. Arch Dis Child 2020;105:810-1.

29. Li A, Harries M, Ross LF. Reopening K-12 schools in the era of coronavirus disease 2019: review of state-level guidance addressing equity concerns. $f$ Pediatr 2020;227:38-44.e7.

30. Chmielewski AK, Khan O. Toronto's rich neighbourhoods opt for in-person school. Medium 2020 Sept. 9. Available: https://medium.com/@katyn_and_ omar/torontos-rich-neighbourhoods-opt-for-in-person-school-8161dc6cc13b (accessed 2021 June 21).

31. COVID-19 in Ontario: a focus on material deprivation: January 15, 2020 to June 3, 2020. Toronto: Ontario Agency for Health Protection and Promotion (Public Health Ontario); 2020. Available: https://www.publichealthontario.ca/-/ media/documents/ncov/epi/2020/06/covid-19-epi-material-deprivation.pdf?la= en (accessed 2021 June 26).

32. Schweiberger K, Hoberman A, Iagnemma J, et al. Practice-level variation in telemedicine use in a pediatric primary care network during the COVID-19 pandemic: retrospective analysis and survey study. 7 Med Internet Res 2020;22: e24345.

33. Vaccine coverage by neighbourhood COVID-19 risk in immigrants, refugees, and other newcomers, up to April 26, 2021. Toronto: ICES; 2021.

34. Marcin JP, Shaikh U, Steinhorn RH. Addressing health disparities in rural communities using telehealth. Pediatr Res 2016;79:169-76.

35. Wilcock AD, Rose S, Busch AB, et al. Association between broadband internet availability and telemedicine use. 7AMA Intern Med 2019;179:1580-2.

36. Brownell M, Chartier M, Santos R, et al. How are Manitoba's children doing? 2nd ed. Winnipeg: Manitoba Centre for Health Policy; 2012.

37. Buajitti E, Chiodo S, Rosella LC. Agreement between area- and individuallevel income measures in a population-based cohort: implications for population health research. SSM Popul Health 2020;10:100553.

38. Glazier RH, Zagorski BM, Rayner J. Comparison of primary care models in Ontario by demographics, case mix and emergency department use, 2008/09 to 2009/10. Toronto: ICES; 2012.

Affiliations: The Hospital for Sick Children (Saunders, Guttmann, Cohen); Department of Paediatrics (Saunders, Guttmann, Cohen), University of Toronto; ICES Central (Saunders, Guttmann, Cohen, Fu, Guan, Gandhi, Stukel); Child Health Evaluative Sciences (Saunders, Guttmann, Cohen, Fiksenbaum), SickKids Research Institute; Institute of Health Policy, Management and Evaluation (Saunders, Guttmann, Cohen, Stukel), Temerty Faculty of Medicine (Saunders, Guttmann, Cohen) and Edwin S.H. Leong Centre for Healthy Children (Saunders, Guttmann, Cohen), University of Toronto, Toronto, Ont.; Department of Community Health Sciences (Brownell, Mahar, Katz), University of Manitoba; Manitoba Centre for Health Policy (Brownell, Sarkar, Mahar, Katz, Eze); Children's Hospital Research Institute of Manitoba (Brownell); Department of Family Medicine (Katz), University of Manitoba, Winnipeg, Man.

Contributors: Natasha Saunders, Therese Stukel, Astrid Guttmann, Eyal Cohen and Marni Brownell conceived and designed the study. Longdi $\mathrm{Fu}$, Jun Guan and Joykrishna Sarkar acquired and analyzed the data. Natasha Saunders, Therese Stukel, Astrid Guttmann, Eyal Cohen, Marni Brownell, Sima Gandhi, Alyson Mahar, Alan Katz and Nkiruka Eze interpreted the data. Natasha Saunders drafted the manuscript. All of the authors revised the manuscript critically for important intellectual content, approved the final version to be published and agreed to be accountable for all aspects of the work. 
Funding: This study was supported by ICES, which is funded by an annual grant from the Ontario Ministry of Health. This study was also supported by the Canadian Institutes of Health Research grant VR4172730 awarded to Astrid Guttmann, Natasha Saunders, Eyal Cohen and Marni Brownell, and a Creative Professional Activity grant from the Department of Paediatrics, The Hospital for Sick Children awarded to Natasha Saunders, Astrid Guttmann and Eyal Cohen.

Acknowledgements: The authors acknowledge the Manitoba Centre for Health Policy for use of data contained in the Manitoba Population Research Data Repository under project HIPC No. 2020/2021-34. Manitoba data used in this study were derived from data provided by Manitoba Health and by Immigration, Refugees and Citizenship Canada.

Content licence: This is an Open Access article distributed in accordance with the terms of the Creative Commons Attribution (CC BY-NCND 4.0) licence, which permits use, distribution and reproduction in any medium, provided that the original publication is properly cited, the use is noncommercial (i.e., research or educational use), and no modifications or adaptations are made. See: https://creativecommons.org/licenses/by-nc -nd $/ 4.0 \%$.

Data sharing: The data sets from this study are held securely in coded form at ICES and the Manitoba Centre for Health Policy (MCHP).
Data-sharing agreements prohibit ICES and MCHP from making the data sets publicly available, but access may be granted to those who meet prespecified criteria for confidential access, available at https://www.ices. on.ca/DAS and https://www.umanitoba.ca/faculties/health_sciences/ medicine/units/chs/departmental_units/mchp/resources/access.html. The full data set creation plan and underlying analytic code are available from the authors on request, with the understanding that the programs may rely on coding templates or macros that are unique to ICES and MCHP.

Disclaimer: The opinions, results and conclusions reported in this article are those of the authors and are independent from the funding sources. No endorsement by ICES or the Ontario Ministry of Health is intended or should be inferred. Parts of this material are based on data and information compiled and provided by the Canadian Institute for Health Information (CIHI) and Immigration, Refugees and Citizenship Canada (IRCC). However, the analyses, conclusions, opinions and statements expressed herein are those of the authors and not necessarily those of CIHI or IRCC. No official endorsement by the Manitoba Centre for Health Policy, Manitoba Health or other data providers is intended or should be inferred.

Supplemental information: For reviewer comments and the original submission of this manuscript, please see www.cmajopen.ca/content/9/4/ E1149/suppl/DC1. 